This document is the Accepted Manuscript version of a Published Work that appeared in final form in ACS Energy Letters, copyright (C) American Chemical Society after peer review and technical editing by the publisher.

To access the final edited and published work see ACS Energy Letters 2017, 2, 549-555

https://doi.org/10.1021/acsenergylett.7b00047

Also see same web-link for Supporting Information, available free of charge. 


\title{
Electrochemical Reduction of Carbon Dioxide to Methanol in the Presence of Benzannulated Dihydropyridine Additives
}

\author{
Patrick K. Giesbrecht ${ }^{a}$ and David E. Herbert ${ }^{a, b *}$ \\ ${ }^{a}$ Department of Chemistry and ${ }^{b}$ Manitoba Institute for Materials, University of Manitoba, \\ 144 Dysart Rd, Winnipeg, MB, Canada R3T 2N2
}

\begin{abstract}
Dihydropyridines (DHPs) have been postulated as active intermediates in the pyridine-mediated electrochemical conversion of $\mathrm{CO}_{2}$ to methanol, however the ability of isolated DHPs to facilitate methanol production in a similar fashion to their parent aromatic $\mathrm{N}$-heterocycles (ANHs) has not been tested. Here, we use bulk electrolysis to show that 1,2- and 1,4-DHPs (1,2-dihydrophenanthridine and 9,10dihydroacridine) can mediate the sub-stoichiometric electrochemical reduction of $\mathrm{CO}_{2}$ to methanol and formate with similar Faradaic efficiencies as the corresponding ANHs at Pt electrodes. 1,2-dihydrophenanthridine furthermore exhibits improved $\mathrm{CO}_{2}$ reduction activity compared to its parent ANH (phenanthridine) at glassy carbon electrodes. These results provide the first experimental evidence for the participation of DHPs as additives in electrochemical $\mathrm{CO}_{2}$ reduction.
\end{abstract}

\section{TOC GRAPHIC}

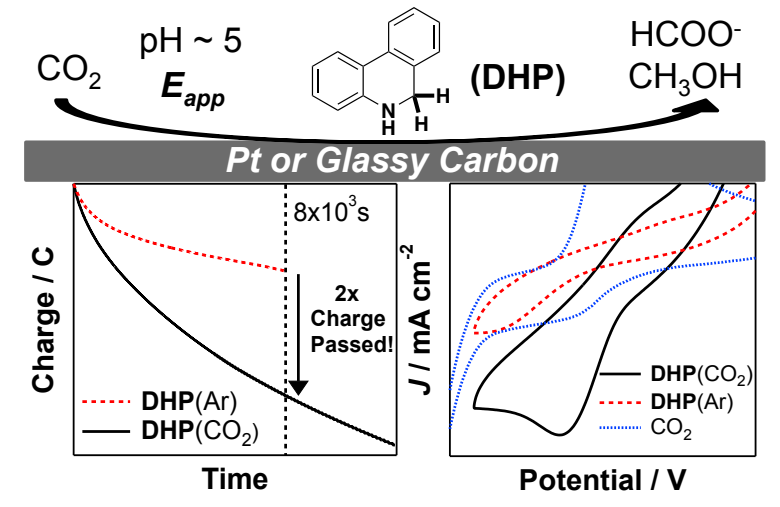


The recycling of $\mathrm{CO}_{2}$ directly to liquid chemicals using water and a renewable energy source is a promising route to sustainable carbon-based fuels. ${ }^{1-2}$ Reports that the addition of simple aromatic $N$-heterocycles (ANHs) such as pyridine (1) leads to the production of methanol in acidic aqueous electrochemical ${ }^{3-6}$ and photochemical ${ }^{7-11}$ cells at low overpotentials or light-driven underpotentials have garnered both justifiable excitement ${ }^{12}$ and a healthy amount of scrutiny. ${ }^{13-14}$ Recent studies ${ }^{10,15-17}$ have verified that methanol is indeed produced and only in the presence of ANH additives, but also that multi-e-/multi$\mathrm{H}^{+}$reduced products such as methanol and formic acid are generated with low, substoichiometric turnover numbers (TONs; $0.04-0.33$ ) with product selectivity and Faradaic efficiencies $(\% \mathrm{FE})$ dependent on the nature of the electrode used. ${ }^{3-4,7-8,15,18-19}$

Given the promise of this simple system, the role of the ANH additive, the acidic solution and the electrode surface in the overall mechanism have been subject to ongoing debate. Computational studies from Carter, Musgrave, and furthered by Keith, suggest a critical role for $2 \mathrm{e}^{-} / 2 \mathrm{H}^{+}$reduced dihydropyridines (DHPs) as intermediates (Figure 1), ${ }^{20-23}$ either formed in solution ${ }^{22}$ or adsorbed to the electrode surface. ${ }^{20,24} \mathrm{~A}$ 'weak-acid mechanism' 13,25 has also been proposed where the conjugate acid of the ANH additive is reduced at the electrode surface to form adsorbed hydrogen, $H_{\text {ads }}$, which then participates in proton-coupled hydride transfer (PCHT) with a second equivalent of $[\mathrm{ANH}-\mathrm{H}]^{+}$to facilitate $\mathrm{CO}_{2}$ reduction ${ }^{26-27}$ but can also participate in hydrogen evolution.

Despite their prominence in computed mechanisms, the ability of isolated DHPs themselves to facilitate methanol production in a similar fashion to parent ANHs has to date not been tested. We hypothesized that if DHPs are competent intermediates, they should exhibit comparable activities to their parent ANHs. We therefore screened isolated 


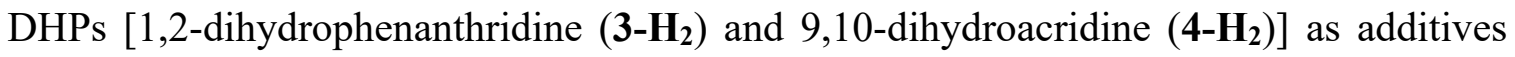
in electrochemical $\mathrm{CO}_{2}$ reduction at both Pt and glassy carbon electrodes.

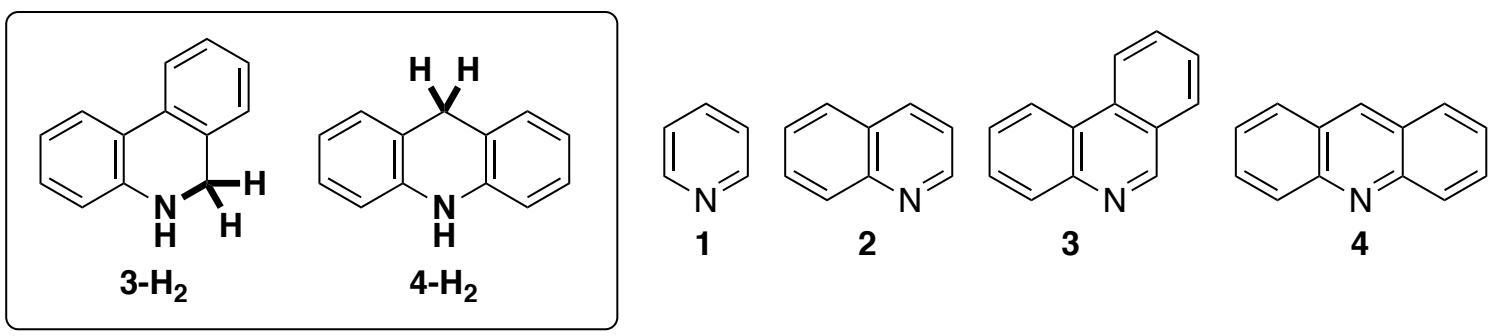

Figure 1. Structures of DHPs and related ANHs studied as additives in this work.

DHPs 3- $\mathbf{H}_{\mathbf{2}}$ and $\mathbf{4}-\mathbf{H}_{\mathbf{2}}$ are chemically similar to the 1,2- and 1,4-DHP isomers of $\mathbf{1}-\mathbf{H}_{\mathbf{2}}$ proposed as intermediates in pyridine-mediated $\mathrm{CO}_{2}$ reduction (Figure 1). While a purely aqueous electrochemical system is more ideal for fuel-forming purposes, a mixed aqueous/organic solvent system was utilized here for solubility reasons. ${ }^{28}$ Accordingly, we also evaluated the activities of the parent ANHs phenanthridine (3; 3,4benzoquinoline) and acridine (4; 2,3-benzoquinoline), as well as those of pyridine (1) and quinoline (2) in this mixed solvent system to enable comparisons with DHPs $\mathbf{3}-\mathbf{H}_{\mathbf{2}}$ and $\mathbf{4 -}$ $\mathbf{H}_{2}$.

Bulk electrolyses were conducted to quantify yields of liquid fuel candidates methanol and formate. ${ }^{29}$ Potentiostatic electrolyses were used to ensure selectivity of the reductive processes, with $E_{\text {applied }}$ and the charge passed chosen based on previously reported optimizations for $\mathbf{1}^{17}$ with a shift in the potential scale vs $\mathrm{Fc}^{0 /+}$ due to the use of a mixture of solvents taken into account for accurate comparison of $E_{\text {applied. }}{ }^{30}$ The $E_{\text {applied }}=-0.75 \mathrm{~V}$ vs $\mathrm{Fc}^{0 /+}$ used for experiments at $\mathrm{Pt}$ is at the onset of the reduction peak observed by $\mathrm{CV}$ for all the ANHs under $\mathrm{CO}_{2}$ (Figure 3), while for reticulated vitreous carbon (RVC) electrodes $E_{\text {applied }}=-1.20 \mathrm{~V} \mathrm{vs} \mathrm{Fc}^{0 /+}$, at the onset of the reduction peaks observed in CVs 
for 1-3 at GCEs (Figure S9). Potentials were applied for $c a$. $10000 \mathrm{~s}$ (see SI for CPE curves), with multiple analytical techniques ( ${ }^{1} \mathrm{H}$ NMR, GC-MS, GC-FID and LC-MS; see SI for experimental details and integration methods) employed to corroborate identification of specific organic products. Care was taken to address the potential for contamination during sample preparation and analysis (see SI). ${ }^{14}$

From the GC and LC traces (see SI for chromatograms), the absolute yields of products obtainable under the conditions employed are low (10-250 $\mu \mathrm{M}$ methanol and/or formate), consistent with absolute amounts observed in previous reports measuring the activity of $\mathbf{1}$ in aqueous electrochemical cells..$^{3-4,7-8,15,17-18}$ As a result, the TONs we report for this system are sub-stoichiometric relative to the amount of DHP/ANH added (Table 1), in line with the literature on $\mathbf{1}$. The accuracy of the analytical techniques employed was checked using standard solutions, and the precision evaluated by running samples in triplicate and over a span of three months. The largest component of the error in our reported values based on GC-FID is attributed to sample-to-sample reproducibility in bulk electrolysis rather than the detection limit or consistency of the instruments used. ${ }^{1} \mathrm{H}$ NMR ( 3.24 ppm, see SI) and GC-MS corroborated the identification of methanol. The LC-MS method used for formic acid quantification proved less sensitive, and as such larger corresponding errors were determined for the reported values.

For DHPs $\mathbf{3}-\mathbf{H}_{2}$ and $\mathbf{4}-\mathbf{H}_{2}, \% \mathrm{FEs}$ determined from bulk electrolysis experiments at $\mathrm{Pt}$ are comparable with those observed for parent ANHs 3 and 4 (Table 1). Analysis of the electrolyzed reaction mixture by ${ }^{1} \mathrm{H}$ NMR showed that $\sim 40 \%$ of $\mathbf{3}-\mathbf{H}_{\mathbf{2}}$ is converted to $\mathbf{3}$ after $\mathrm{CO}_{2}$ reduction at $\mathrm{Pt}$ surfaces (Figure S19), with similar conversion of $\mathbf{4}-\mathbf{H}_{2}$ to 4 under the same conditions. In comparison, potentiostatic electrolysis of $\mathbf{3}-\mathbf{H}_{\mathbf{2}}$ at the same 
$\mathrm{pH}$ under $\mathrm{Ar}$ (in the absence of $\mathrm{CO}_{2}$ ) resulted in an order of magnitude lower conversion of $3-\mathrm{H}_{2}$ to 3 (Figure S26), and 50\% less charge passed compared to under $\mathrm{CO}_{2}$ (Figure 2a). This is consistent with the majority of the reactivity of the DHP and charge passed attributable to reaction of the DHP with $\mathrm{CO}_{2}$. The observed methanol and formic acid are therefore not simply products of an ANH-mediated process resulting from conversion of the DHP to its parent ANH under the conditions employed.
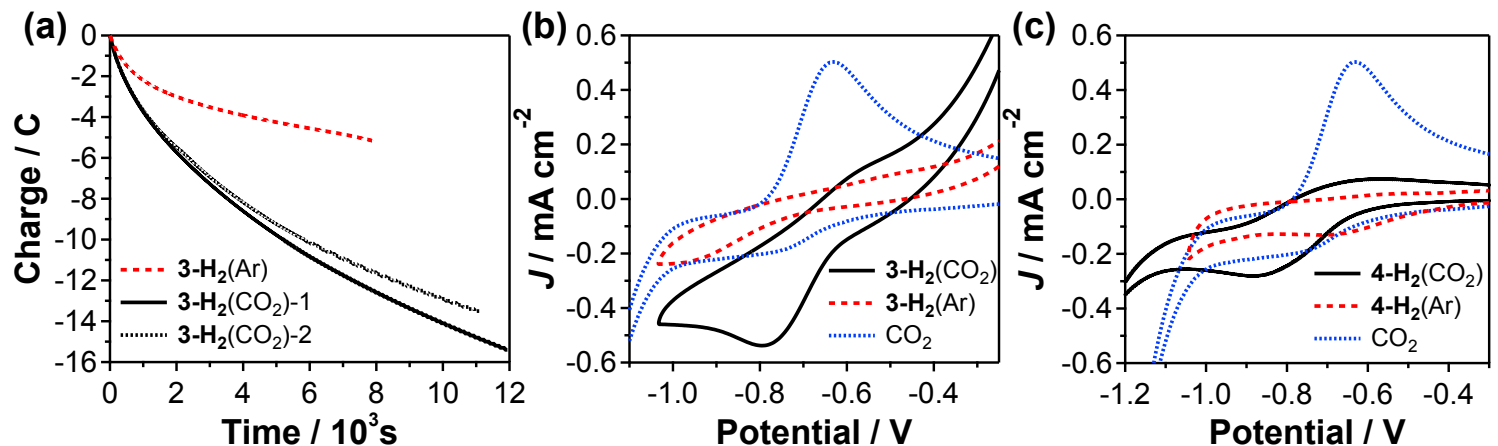

Figure 2. (a) Charge passed in bulk electrolyses of $10 \mathrm{mM} \mathrm{3- \mathbf {H } _ { 2 }}\left(E_{\text {applied }}=-0.75 \mathrm{~V}\right.$ vs $\mathrm{Fc}^{0 /+}, \mathrm{Pt}$ mesh electrode) under $\mathrm{Ar}$ (red dash) and two separate runs under $\mathrm{CO}_{2}$ (black

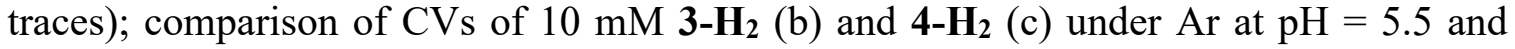
under $\mathrm{CO}_{2}$ (black) with $\mathrm{CO}_{2}$ alone (blue), $v=100 \mathrm{mV} / \mathrm{s} ; 0.1 \mathrm{M} \mathrm{LiClO}$ in $\mathrm{CH}_{3} \mathrm{CN} / \mathrm{H}_{2} \mathrm{O}$ $(40 \% \mathrm{v} / \mathrm{v}), \mathrm{Pt} \operatorname{disc} ; E \mathrm{vs} \mathrm{Fc}{ }^{0 /+}$.

Furthermore, electrolysis of $\mathbf{3}-\mathbf{H}_{\mathbf{2}}$ at RVC also led to methanol and formate production with similar $\% \mathrm{FE}$ as seen at Pt electrodes, and with higher $\% \mathrm{FE}$ than observed for 3 . This demonstrates that isolated DHPs can function as additives in a similar fashion to their parent ANHs, which is consistent with the proposed role of DHPs as intermediates relevant in $\mathrm{ANH}-$ mediated reduction of $\mathrm{CO}_{2}$ to methanol. ${ }^{21-24}$ No reduced products were detected when electrolysis of $\mathbf{3}-\mathbf{H}_{2}$ under $\mathrm{CO}_{2}$ was performed at a lower potential $(-0.75$ $\mathrm{V}$ vs. $\left.\mathrm{Fc}^{0 /+}\right)$ at $\mathrm{RVC}$ electrodes. 
Table 1. Faradaic efficiencies for electrochemical $\mathrm{CO}_{2}$ reduction in the presence of DHP or ANH additives

\begin{tabular}{|c|c|c|c|c|c|c|c|}
\hline Additive & Electrode & $\begin{array}{c}\% \mathrm{FE}^{a} \\
\mathrm{CH}_{3} \mathrm{OH}\end{array}$ & $\begin{array}{l}\% \mathrm{FE}^{b, c} \\
\mathrm{HCOO}^{-}\end{array}$ & $\begin{array}{c}\mathrm{TON} \mathrm{\textrm {CH } _ { 3 } \mathrm { OH }} \\
\left(10^{-3}\right)\end{array}$ & $\begin{array}{c}\text { TOF } \\
\mathrm{CH}_{3} \mathrm{OH} \\
\left(\mathbf{1 0}^{-3} \mathrm{hr}^{-1}\right)\end{array}$ & $\begin{array}{c}\text { TON } \\
\text { HCOO- }^{-} \\
\left(10^{-3}\right)\end{array}$ & $\begin{array}{c}\text { TOF } \\
\mathrm{HCOO}^{-} \\
\left(10^{-3} \mathrm{hr}^{-1}\right)\end{array}$ \\
\hline 1 & $\mathrm{Pt}$ & $30(10)$ & not det. & $12.0(1.0)$ & $4.3(4)$ & - & - \\
\hline 1 & RVC & $7(7)$ & $1.0(0.3)$ & $0-4$ & $0-1$ & $0.76(24)$ & $0.27(8)$ \\
\hline 2 & $\mathrm{Pt}$ & $36(16)$ & $4(6)$ & $15(7)$ & $5.2(2.7)$ & $6.6(9)$ & $2.1(4)$ \\
\hline 2 & RVC & $11(7)$ & $4(3)$ & $3.9(1.9)$ & $1.4(9)$ & $0.8-20$ & $0.2-5$ \\
\hline 3 & $\mathrm{Pt}$ & $12(8)$ & $4(1)$ & $7(3)$ & $2.5(1.2)$ & $5.4(1.0)$ & $1.9(4)$ \\
\hline 3 & RVC & $5(3)$ & $1.1(0.2)$ & $2.2(1.6)$ & $0.8(6)$ & $1.56(22)$ & $0.54(19)$ \\
\hline $3-\mathrm{H}_{2}$ & $\mathrm{Pt}$ & $19(7)$ & $3(4)$ & $9(3)$ & $1.9(5)$ & $0-8$ & $0-2$ \\
\hline $3-\mathrm{H}_{2}$ & RVC & $15(7)$ & $8(3)$ & $4.3(2.4)$ & $1.3(6)$ & $5.9(2.2)$ & $1.9(8)$ \\
\hline 4 & $\mathrm{Pt}$ & $17(13)$ & not det. & $6(4)$ & 2.1(1.6) & - & - \\
\hline 4 & RVC & $-d$ & $-^{d}$ & - & - & - & - \\
\hline $4-\mathrm{H}_{2}$ & $\mathrm{Pt}$ & $13(10)$ & not det. & $4(3)$ & $1.2(9)$ & - & - \\
\hline 4- $\mathrm{H}_{2}$ & RVC & $-^{d}$ & $-{ }^{d}$ & - & - & - & - \\
\hline
\end{tabular}

${ }^{a}$ Via peak area of GC-FID traces (see SI) with standard deviation of bulk electrolysis samples. ${ }^{b}$ Via peak area from LC-MS traces (see SI). ${ }^{c}$ Signals for ANH overlap with product signals in ${ }^{1} \mathrm{H}$ NMR. ${ }^{d}$ Significant electrode fouling (deposition).

Turning to the ANHs themselves, $\mathrm{CO}_{2}$ reduction in the presence of an $\mathrm{ANH}$ additive was also seen at more inert electrode surfaces (RVC) at more reducing potentials. ${ }^{31} \mathbf{1 - 3}$ all exhibit a significant drop in $\% \mathrm{FE}$ going from $\mathrm{Pt}$ to $\mathrm{RVC}$ electrodes with no products detected at a lower $E_{\text {applied }}\left(-0.75 \mathrm{~V}\right.$ vs. $\left.\mathrm{Fc}^{0 /+} ; \mathrm{RVC}\right)$. The $\% \mathrm{FEs}$ determined in this work for $\mathbf{1}$ are slightly higher, though not statistically different within error, than $\% \mathrm{FEs}$ found reported for aqueous cells in the literature, though we note that in a mixed organic/aqueous solvent system $\mathrm{CO}_{2}$ is expected to be more soluble, ${ }^{32}$ and direct comparisons to literature \%FEs should be made cautiously. Quinoline (2), recently proposed as a viable ANH additive on thermodynamic considerations, ${ }^{33}$ exhibits the highest overall $\% \mathrm{FE}$ and the highest methanol production of the series at both electrode surfaces. Pyridine (1) and acridine (4) exhibit the highest selectivity for methanol 
formation, with no formate observed by ${ }^{1} \mathrm{H}$ NMR or LC-MS at Pt, indicating only trace amounts produced under our experimental conditions.

Unlike the correlation between $\mathrm{p} K_{\mathrm{a}}$ and total Faradaic yields previously reported for a series of substituted pyridines in water, ${ }^{5}$ the highest overall activity of 1-4 is observed for the ANH with an intermediate $\mathrm{p} K_{\mathrm{a}}(\mathbf{2})$. Lower $\% \mathrm{FEs}$ are observed for ANHs with higher $(\mathbf{1}, \mathbf{4})$ and lower $(\mathbf{3}) \mathrm{p} K_{\mathrm{a}}$ 's. ${ }^{34}$ The ease with which an ANH participates in a 'weak acid' reduction to form $\mathrm{H}_{\mathrm{ads}}$ is apparently not $\% \mathrm{FE}$ determining in our system. This agrees with the observation that acetic acid, which has a $\mathrm{p} K_{\mathrm{a}}$ close to $[\mathbf{1}-\mathbf{H}]^{+}$, does not mediate methanol production..$^{25}$

To put into context the hydride donor ability of the DHPs, Musgrave estimated the hydride nucleophilicity $(N)$ of $\mathbf{3}-\mathbf{H}_{2}\left(N_{3-\mathbf{H} 2} \sim 8.1\right)$ to be comparable to the experimentally determined value for the well-known hydride donor Hantzsch's ester $(N=9.00)$. The experimentally determined value for 10-methyl-9,10-dihydroacridine, the $N$-methyl derivative of $\mathbf{4}-\mathbf{H}_{2}$, is $N=5.54$, while the 1,2 -isomer of $\mathbf{1}-\mathbf{H}_{\mathbf{2}}$ is estimated to be the strongest DHP hydride donor $(N \sim 11.4) .{ }^{22}$ The hydride nucleophilicity of ortho-1,2dihydroquinoline $\left(\mathbf{2}-\mathbf{H}_{\mathbf{2}}\right)$ is reasoned to be intermediate between that of ortho-1,2-

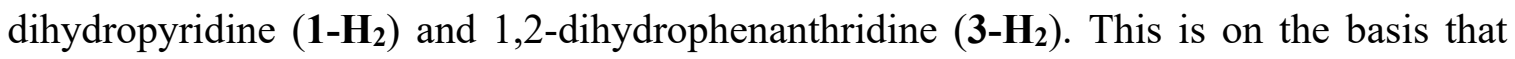
the remaining olefinic sub-unit in the partially hydrogenated ortho- $\mathbf{2}-\mathbf{H}_{2}$ retains conjugation with an intact aromatic benzo ring and is therefore stabilized with respect to the diene fragment of $\mathbf{1}-\mathbf{H}_{2}$. In comparison, formation of $\mathbf{3}-\mathbf{H}_{2}$ or $\mathbf{4}-\mathbf{H}_{2}$ leaves in tact two aromatic benzo subunits. The reactivity of the isolated $\mathrm{C}=\mathrm{N}$ bond towards hydrogenation in $\mathbf{3}$ is highlighted by the fact that the 'imine-bridged, biphenyl' resonance contributor dominates the ground state structure of $\mathbf{3}$, in accordance with Clar's postulate. ${ }^{35}$ All have 
been calculated to be competent hydride donors for $\mathrm{CO}_{2}$ reduction based on thermodynamic considerations. ${ }^{22,33} \mathbf{3}-\mathbf{H}_{\mathbf{2}}$ has been used in the transfer hydrogenation of $\mathrm{C}=\mathrm{O}$ bonds in $\alpha$-ketoesters. ${ }^{36-37}$

Combined with the calculated or experimental hydride nucleophilicities of the rest of the series, we estimate an order of decreasing hydride donor ability from $\mathbf{1 - \mathbf { H } _ { 2 }}>\mathbf{2}-\mathbf{H}_{\mathbf{2}}>$

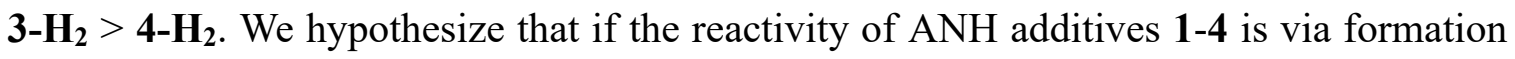
of a DHP, the comparably high activity of $\mathbf{2}$ is derived from a balance between the Lewis acidity of the parent ANH (ease of formation of a DHP, lower susceptibility to side reactions) and hydride donor ability of the DHP once formed. Keith has similarly proposed on the basis of quantum chemistry thermodynamic calculations that ANHmediated multi-e/multi- $\mathrm{H}^{+} \mathrm{CO}_{2}$ may be governed by the Sabatier Principle, where Brønsted acidity and hydride donor ability must be balanced to manage both $\mathrm{H}^{+}$and $\mathrm{H}^{-}$ transfer to $\mathrm{CO}_{2} \cdot{ }^{33}$ While phenanthridine (3) and acridine (4) mediate reduction of $\mathrm{CO}_{2}$ with similar \%FEs, 4 additionally undergoes a more prominent deposition process (see Figure S6). Access to ortho- (available in 3, not available in 4) or para-positions (available in 4, not available in 3) likely governs the interaction of an ANH at the electrode surface. Electrochemical deposition of 1,10-phenanthroline in acid, for example, was shown to occur via covalent modification of GCE surfaces through the para-position of the ANH. ${ }^{38-39}$

The differences in \%FE observed at Pt compared with RVC for the ANH series and the lower applied potential is consistent with an important role for the electrode surface in the observation of $\mathrm{CO}_{2}$ reduction. ${ }^{20-21,24,40}$ Nevertheless, we tested the possibility of a homogeneous reaction between $\mathrm{CO}_{2}$ and DHPs $\mathbf{3}-\mathbf{H}_{2}$ and $\mathbf{4}-\mathbf{H}_{2}$ by conducting NMR scale 
reactions of $3-\mathrm{H}_{2} / \mathbf{4}-\mathrm{H}_{2}$ under $\mathrm{CO}_{2}(1 \mathrm{~atm})$ in $\mathrm{CD}_{3} \mathrm{CN} / \mathrm{D}_{2} \mathrm{O}(1: 0.1 \mathrm{v}: \mathrm{v})$ to probe the chemical reactivity in the absence of an electrode surface or applied potential. ${ }^{1} \mathrm{H}$ NMR analysis showed no observable conversion of DHP to ANH at room temperature, and no $\mathrm{CO}_{2}$-derived products, $\mathrm{H}_{2}$ generation, or $\mathrm{H} / \mathrm{D}$ scrambling (Figures $\mathrm{S} 23-\mathrm{S} 24$ ), in agreement with reported results for $\mathbf{1} / \mathbf{1}-\mathbf{H}_{\mathbf{2}}$ mixtures and $\mathbf{1}$ with Pt nanoparticles. ${ }^{9,25}$ The absence of direct chemical reaction suggests that participation of the electrode surface and an applied potential is critical for $\mathrm{CO}_{2}$ reduction mediated by a pre-formed DHP in an electrochemical system..$^{24,41-42}$

CVs of DHPs 3- $\mathbf{H}_{2} / 4-\mathbf{H}_{2}$ in the absence of $\mathrm{CO}_{2}$ showed no reductive events in initial cathodic scans of neutral or acidic solutions at Pt (Figure 2b) or GCE (Figure S11). Cathodic current can be observed after cycling through a $2 \mathrm{e}^{-} / 2 \mathrm{H}^{+}$electrochemical oxidation $\left(0.3-0.5 \mathrm{~V} v \mathrm{Fc}^{0 /+}\right)$, with this new reductive event accordingly assigned to reduction of newly formed $[3-\mathrm{H}]^{+} /[4-\mathrm{H}]^{+}$(Figure S11). ${ }^{43}$ Introduction of $\mathrm{CO}_{2}$ results in the appearance of an irreversible reduction at $-0.8{\mathrm{~V} \mathrm{vs} \mathrm{Fc}^{0 /+}}^{0}$ when the potential is initially swept from the open circuit potential for $\mathbf{3}-\mathbf{H}_{2}$, with a large current enhancement compared to the initial cathodic scan under acidic conditions ( $\mathrm{Ar}$ ) and for a $\mathrm{CO}_{2}$ saturated solution without any $\mathbf{3}-\mathbf{H}_{2}$ present (Figure $2 \mathrm{~b}$ ). At the potentials applied in the bulk electrolysis reactions, DHPs $\mathbf{3}-\mathbf{H}_{\mathbf{2}} / \mathbf{4}-\mathbf{H}_{\mathbf{2}}$ therefore only exhibit an appreciable current response by $\mathrm{CV}$ at the scan rates examined in the presence of $\mathrm{CO}_{2}$. In other words, for pre-formed DHPs, all four components $-\mathbf{3}-\mathrm{H}_{2}, \mathrm{CO}_{2}$, an electrode and a sufficiently reducing potential - are required to observe methanol production in bulk electrolysis, and current enhancement by $\mathrm{CV}$. 
In comparison, $\mathrm{CVs}$ of $\mathrm{ANHs} \mathbf{1 - 4}$ at $\mathrm{Pt}$ in the absence of $\mathrm{CO}_{2}$ but under similar acidic conditions show a quasi-reversible reduction at $\sim-0.7 \mathrm{~V}$ vs $\mathrm{Fc}^{0 /+}$, with a scan rate dependence corresponding to diffusion control (see SI). A linear correlation is observed between $E_{1 / 2}$ and $\mathrm{ANH} \mathrm{p} K_{\mathrm{a}}$, with a slope of $-0.054 \mathrm{mV} /[$ unit $\mathrm{pH}]$, indicating the 'weak acid' relationship observed in water ${ }^{13,25}$ is preserved in mixed $\mathrm{CH}_{3} \mathrm{CN} / \mathrm{H}_{2} \mathrm{O}$ (see Figure S1, Equation 1 in SI).

Introduction of $\mathrm{CO}_{2}$ to the $\mathrm{ANH}$ solution results in an increase in the current observed on the CV timescale for $\mathbf{1 - 3}$ (Figure 3), though only for $\mathbf{1}$ and $\mathbf{2}$ is the enhancement above the sum of the background currents $\left(J_{\mathrm{ANH} /[\mathrm{ANH}-\mathrm{H}]^{+}}+J_{\mathrm{CO} 2}\right)$ at the scan rates employed. In aqueous solution, increased cathodic current for solutions of $\mathbf{1}$ in the presence of $\mathrm{CO}_{2}$ was only detected at scan rates less than $10 \mathrm{mVs}^{-1} .{ }^{44}$ For $\mathbf{3}$, the enhancement is not significant compared to the sum of the background currents $\left(J_{3 /[3-\mathrm{H}]^{+}}+J_{\mathrm{CO} 2}\right.$; Figure $\left.3 \mathrm{c}\right){ }^{13,19}$ At the scan rates employed $(100 \mathrm{mV} / \mathrm{s})$, this current enhancement is likely a result of the presence of dissolved $\mathrm{CO}_{2} / \mathrm{H}_{2} \mathrm{CO}_{3}$ in solution as described previously. ${ }^{13,44}$ In a recent study, Rybchenko et al. confirmed that, in addition to methanol production, hydrogen evolution is the dominant electrochemical reaction in 1-containing aqueous electrolyte solution at $\mathrm{Pt}$, even under high $\mathrm{CO}_{2}$ pressure. Methanol production with $\% \mathrm{FE}$ of up to $10 \%$ for the first $5-10 \mathrm{C} \mathrm{cm}^{-2}$ can be reproducibly detected but only after $c a .1 \mathrm{hr}$ of electrolysis. ${ }^{17}$ As a result, only a small to negligible current enhancement is expected on the $\mathrm{CV}$ timescale ( $\mathrm{ms}$ to $\mathrm{s}$ ) for $\mathrm{CO}_{2}$ reduction in the presence of $\mathrm{ANH}$ additives chemically similar to $\mathbf{1}$.

The reduction processes for 1-4 under $\mathrm{CO}_{2}$ are quasi-reversible, and show features of diffusion control (see Randles-Sevcik plots in SI, Figure S5) with no peak current 
saturation observed, indicating that it is unlikely we are observing an electrocatalytic process on the CV timescale (Figure S4). In comparison, the current enhancement for 3$\mathbf{H}_{2}$ under $\mathrm{CO}_{2}$ is five-fold larger in magnitude with a $25 \%$ increase in the total current passed under $\mathrm{CO}_{2}$ compared to its parent $\mathrm{ANH}$ 3. No current enhancement above the background currents was observed for $\mathbf{4}-\mathbf{H}_{2}$ under $\mathrm{CO}_{2}$, similar to 4 .
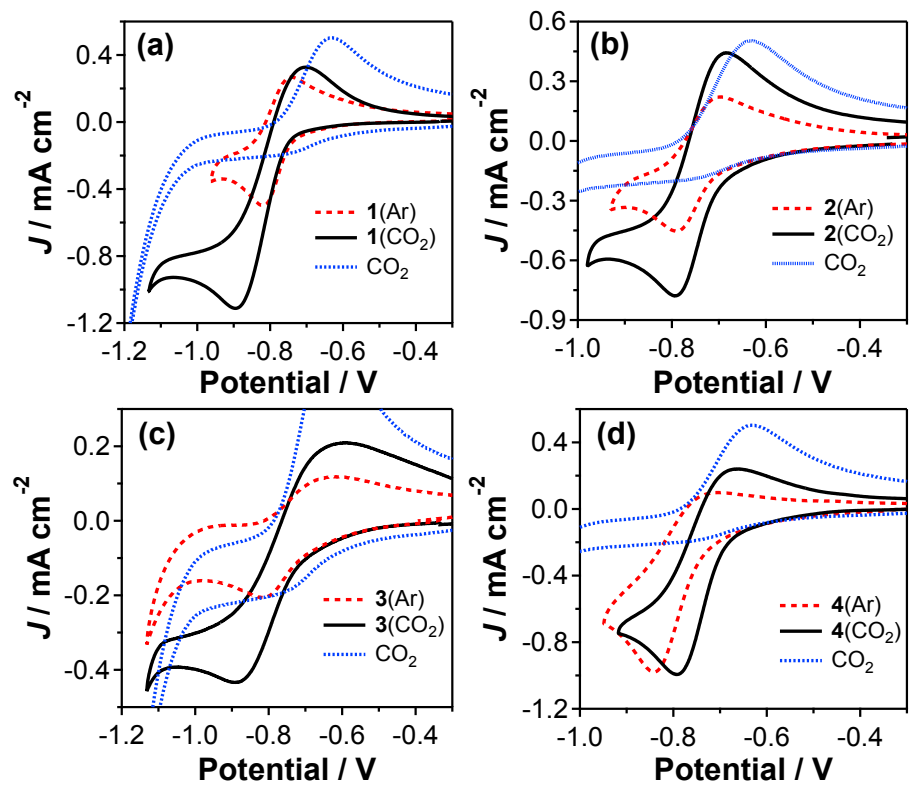

Figure 3. $\mathrm{CVs} 1 \mathrm{~atm} \mathrm{CO}_{2}$ (black); under $\mathrm{Ar}$ in acid (red); and $\mathrm{CO}_{2}$ alone (1 atm, blue) for $10 \mathrm{mM}$ of (a) $1, \mathrm{pH}=5.5$; (b) $2, \mathrm{pH}=5.3$; (c) $3, \mathrm{pH}=5.2$; (d) $4, \mathrm{pH}=5.7 . v=100 \mathrm{mV} / \mathrm{s}$; $0.1 \mathrm{M} \mathrm{LiClO}_{4}, \mathrm{CH}_{3} \mathrm{CN} / \mathrm{H}_{2} \mathrm{O}(40 \% \mathrm{v} / \mathrm{v})$, Pt disc; $E \mathrm{vs} \mathrm{Fc}^{0 /+}$.

Given the electrode dependence of the $\% \mathrm{FEs}$ for $\mathrm{CO}_{2}$ reduction by $\mathrm{ANHs}$ and the absence of product formation by DHPs both without any applied potential or at RVC electrodes at lower $E_{\text {applied }}(-0.75 \mathrm{~V})$, a strictly solution-based DHP mechanism for $\mathrm{CO}_{2}$ reduction appears unlikely. ${ }^{22,45}$ Lessio et al. recently established that a surface-bound 2pyridinyl radical formed via transfer of photoexcited electrons from $\mathrm{p}-\mathrm{GaP}$ to $[\mathbf{1 - H}]^{+}$is thermodynamically feasible in silico, and calculated to be more reactive than the more stable surface-adsorbed DHP $\left[\mathbf{1}-\mathbf{H}_{2}\right]_{\text {ads }}$ (Figure 4a). ${ }^{24}$ Both are proposed as competent intermediates in $\mathrm{ANH}$-mediated photoelectrochemical $\mathrm{CO}_{2}$ reduction at $\mathrm{p}-\mathrm{GaP}$. 
In our system, reactivity via surface-adsorbed $\left[3-\mathbf{H}_{2}\right]_{\text {ads }}$ directly does not account for the appearance of a reductive event in $\mathrm{CVs}$ of $\mathbf{3}-\mathbf{H}_{2}$ under $\mathrm{CO}_{2}$ (Figure 2b). Formation of a surface-bound DHP-derived radical $\left(\mathrm{DHP}^{*}\right.$ ads; Figure $\left.4 \mathrm{~b}\right)$ via $\mathrm{H}_{\mathrm{ads}}$ would explain the observation that different potentials are required for methanol and formate production in bulk electrolyses of DHPs $\mathbf{3}-\mathbf{H}_{2}$ and $\mathbf{4}-\mathbf{H}_{2}$ at RVC compared with $\mathrm{Pt}$, as the surfaces require different potentials for $\mathrm{H}_{\mathrm{ads}}$ formation, and that no homogenous reactivity occurs between $3-\mathrm{H}_{2} / \mathbf{4}-\mathrm{H}_{2}$ and $\mathrm{CO}_{2}$ in the absence of an electrode/potential.

(a) ANH-based $\mathrm{CO}_{2}$ Reduction via $\mathrm{DHP}_{\text {ads }}$ or $\mathrm{DHP}_{\text {ads }}$ (adapted from reference [24])

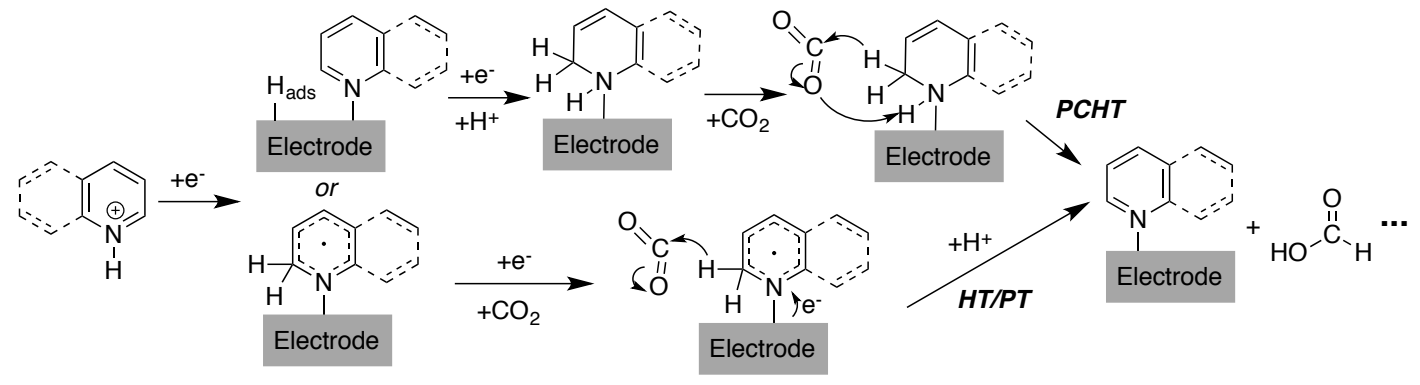

(b) DHP-based $\mathrm{CO}_{2}$ Reduction (this work)

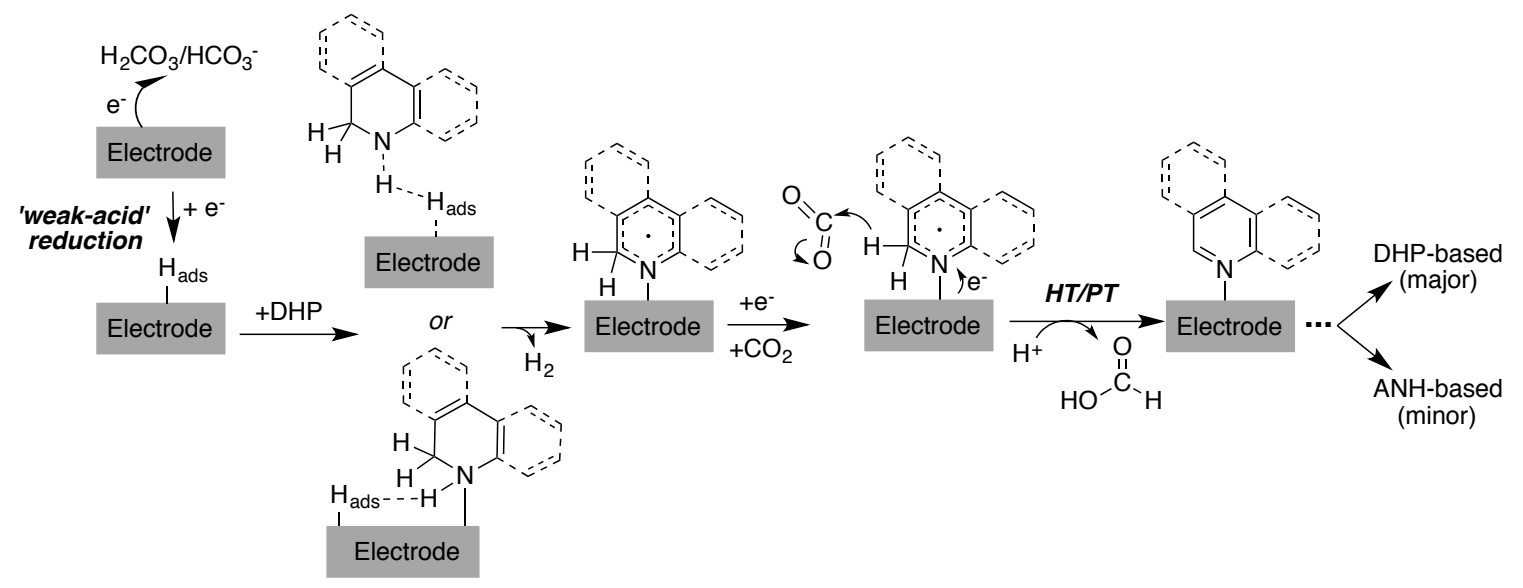

Figure 4. (a) Mechanism for $\mathrm{ANH}$-based $\mathrm{CO}_{2}$ reduction via $\mathrm{DHP}_{\text {ads }}$ or $\mathrm{DHP}^{\bullet}{ }_{\text {ads }}$ adapted from reference ${ }^{24}$, PCHT = proton-coupled hydride transfer; (b) Proposed mechanism for observed $\mathrm{CO}_{2}$ reduction in the presence of isolated DHP additives (this work) via formation of a surface-bound DHP-derived radical, $\mathrm{DHP}^{\cdot}{ }_{\text {ads. }}$. HT $=$ hydride transfer, $\mathrm{PT}=$ proton transfer. Only the initial reduction to $\mathrm{HCOOH}$ is illustrated, with subsequent steps leading to $\mathrm{CH}_{3} \mathrm{OH}$ formation occurring in a similar fashion. 
The mechanism proposed in Figure 4 would account for all the components required to observe methanol production: $\mathbf{3}-\mathrm{H}_{2}, \mathrm{CO}_{2}$, a surface and a sufficiently reducing potential. Participation of $\mathrm{H}_{\mathrm{ads}}$ (formed via 'weak-acid reduction' of carbonic acid in solution, as observed in the background current of $\mathrm{CO}_{2}$ alone, Figure $\left.2 b\right)^{44}$ accounts for the difference in potential required for methanol production at $\mathrm{RVC}$ vs $\mathrm{Pt} . \mathrm{CO}_{2}$ reduction is postulated to then occur via hydride transfer from the DHP-derived surface species, potentially stabilized by surface-organized waters, ${ }^{22}$ followed by proton transfer from the acidic solution completing the initial reduction to formic acid. Bulk electrolyses of ANHs under $\mathrm{CO}_{2}$ in dry, acidified $\mathrm{CH}_{3} \mathrm{CN}$ at $\mathrm{RVC}$ and Pt electrodes resulted in no observable $\mathrm{CO}_{2}$ reduction products, indicating a critical role for water in the reduction mechanism.

The formation of $\mathrm{H}_{\mathrm{ads}}$ also appears to be critical to the activity of ANH additives and we cannot distinguish here a PCHT mechanism ${ }^{27}$ or reactivity of a surface-bound $\mathrm{DHP}_{\text {ads }}$ or DHP-derived radical generated via $\mathrm{H}_{\text {ads, }}$, as proposed by $\mathrm{Carter}{ }^{24}$ The decrease in $\% \mathrm{FE}$ of the ANHs moving from Pt to RVC could result from increased ANH adsorption on RVC surfaces, though only 4 was observed to form a noticeable film after electrolysis under $\mathrm{CO}_{2}$ at $\mathrm{Pt}$ surfaces and after one $\mathrm{CV}$ cycle at GCEs (Figure S6). A poisoning effect at high concentrations of $\mathbf{1}$ on $\mathrm{CuInS}_{2}$ has been attributed to formation of an pyridine adsorption layer that leads to increased resistance to mass transfer. ${ }^{16}$

In conclusion, we present here the first evidence for the participation of isolated dihydropyridine-type species in surface-dependent electrochemical $\mathrm{CO}_{2}$ reduction. This is based on the following observations: (1) methanol and formic acid are generated in electrolyses of isolated DHPs $\mathbf{3}-\mathbf{H}_{2}$ or $\mathbf{4}-\mathbf{H}_{2}$ under $1 \mathrm{~atm}$ of $\mathrm{CO}_{2}$ at both Pt and RVC electrodes; (2) CV and NMR studies show that the parent ANHs 3 and $\mathbf{4}$ are not 
generated from the corresponding DHPs in appreciable amounts in the absence of $\mathrm{CO}_{2}$, ruling out ANH-only mediated activity; (3) no homogeneous reactivity is observed

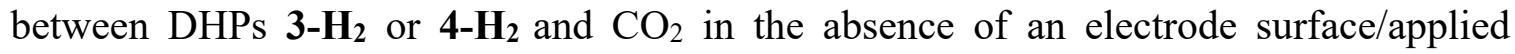
potential; and (4) DHP 3- $\mathbf{H}_{2}$ exhibits an electrode dependence (Pt vs RVC) on the $E_{\text {applied }}$ required to observe methanol production, though not on the observed $\% \mathrm{FE}$.

The ability to carry out electrochemical $\mathrm{CO}_{2}$ to methanol conversion using carbonbased electrodes instead of precious metals such as Pt or Pd is an important milestone for

the scaleability of reduction schemes employing DHP or ANH additives. ${ }^{46-48}$ Consistent with previous studies on $\mathbf{1}$, however, the overall yields of reduced organic products in our experiments remain sub-stoichiometric, even in reactions mediated by pre-formed DHPs. Moreover, we did not observe evidence of electrochemical generation of DHP 3- $\mathbf{H}_{2}$ from ANH 3. These experimental findings will hopefully motivate better understanding of the mechanism of multi- $\mathrm{H}^{+} / \mathrm{e}^{-}$processes occurring in $\mathrm{CO}_{2}$ electrochemical reduction in the presence of simple organic additives, and lead to the improvements in turnover numbers, for example, by targeting biomimetic hydride shuttles capable of cooperative interactions with electrode surfaces and electric potentials..$^{24,49-51}$

\section{ASSOCIATED CONTENT}

Supporting Information. Full experimental details, supporting figures and tables; NMR spectra, GC and LC traces from bulk electrolysis samples (PDF). The Supporting Information is available free of charge on the ACS Publications website.

\section{AUTHOR INFORMATION}

*david.herbert@umanitoba.ca 


\section{Funding Sources}

The Natural Sciences Engineering Research Council of Canada is gratefully acknowledged for a Discovery Grant to DEH (RGPIN-2014-03733) and a CGS-M Fellowship (PKG), as is the University of Manitoba for start-up funding (DEH) and GETS (PKG) support.

\section{ACKNOWLEDGMENT}

We thank Prof. Gregg Tomy for access to a LC-MS; MCAL (Dr. Tom Ward) for access to a GC-MS and GC-FID; Dr. Kirk Marat for assistance with NMR solvent suppression; and Thor Halldorson for helping develop a LC-MS method.

\section{REFERENCES}

(1) Hammarstrom, L.; Hammes-Schiffer, S. Artificial Photosynthesis and Solar Fuels. Acc. Chem. Res. 2009, 42, 1859-1860.

(2) Kumar, B.; Llorente, M.; Froehlich, J.; Dang, T.; Sathrum, A.; Kubiak, C. P. Photochemical and Photoelectrochemical Reduction of $\mathrm{CO}_{2}$. Annu. Rev. Phys. Chem. 2012, 63, 541-569.

(3) Seshadri, G.; Lin, C.; Bocarsly, A. B. A New Homogeneous Electrocatalyst for the Reduction of Carbon Dioxide to Methanol at Low Overpotential. J. Electroanal. Chem. 1994, 372, 145-150.

(4) Barton Cole, E.; Lakkaraju, P. S.; Rampulla, D. M.; Morris, A. J.; Abelev, E.; Bocarsly, A. B. Using a One-Electron Shuttle for the Multielectron Reduction of $\mathrm{CO}_{2}$ to Methanol: Kinetic, Mechanistic, and Structural Insights. J. Am. Chem. Soc. 2010, 132, 11539-11551.

(5) Barton Cole, E. E.; Baruch, M. F.; L'Esperance, R. P.; Kelly, M. T.; Lakkaraju, P. S.; Zeitler, E. L.; Bocarsly, A. B. Substituent Effects in the Pyridinium Catalyzed Reduction of $\mathrm{CO}_{2}$ to Methanol: Further Mechanistic Insights. Top. Catal. 2015, 58, 1522. 
(6) Liao, K.; Askerka, M.; Zeitler, E. L.; Bocarsly, A. B.; Batista, V. S. Electrochemical Reduction of Aqueous Imidazolium on $\mathrm{Pt}(111)$ by Proton Coupled Electron Transfer. Top. Catal. 2015, 58, 23-29.

(7) Barton, E. E.; Rampulla, D. M.; Bocarsly, A. B. Selective Solar-Driven Reduction of $\mathrm{CO}_{2}$ to Methanol Using a Catalyzed p-GaP Based Photoelectrochemical Cell. J. Am. Chem. Soc. 2008, 130, 6342-6344.

(8) Bocarsly, A. B.; Gibson, Q. D.; Morris, A. J.; L. Esperance, R. P.; Detweiler, Z. M.; Lakkaraju, P. S.; Zeitler, E. L.; Shaw, T. W. Comparative Study of Imidazole and Pyridine Catalyzed Reduction of Carbon Dioxide at Illuminated Iron Pyrite Electrodes. ACS Catal. 2012, 2, 1684-1692.

(9) Boston, D. J.; Xu, C.; Armstrong, D. W.; MacDonnell, F. M. Photochemical Reduction of Carbon Dioxide to Methanol and Formate in a Homogeneous System with Pyridinium Catalysts. J. Am. Chem. Soc. 2013, 135, 16252-16255.

(10) Jeon, J. H.; Mareeswaran, P. M.; Choi, C. H.; Woo, S. I. Synergism Between CdTe Semiconductor and Pyridine - Photoenhanced Electrocatalysis for $\mathrm{CO}_{2}$ Reduction to Formic Acid. RSC Adv. 2014, 4, 3016-3019.

(11) Yuan, J.; Hao, C. Solar-Driven Photoelectrochemical Reduction of Carbon Dioxide to Methanol at $\mathrm{CuInS}_{2}$ Thin Film Photocathode. Sol. Energy Mater. Sol. Cells 2013, 108, 170-174.

(12) White, J. L.; Baruch, M. F.; Pander, J. E., III; Hu, Y.; Fortmeyer, I. C.; Park, J. E.; Zhang, T.; Liao, K.; Gu, J.; Yan, Y. et al. Light-Driven Heterogeneous Reduction of Carbon Dioxide: Photocatalysts and Photoelectrodes. Chem. Rev. 2015, 115, 1288812935.

(13) Costentin, C.; Canales, J. C.; Haddou, B.; Savéant, J.-M. Electrochemistry of Acids on Platinum. Application to the Reduction of Carbon Dioxide in the Presence of Pyridinium Ion in Water. J. Am. Chem. Soc. 2013, 135, 17671-17674.

(14) Savéant, J.-M.; Tard, C. Attempts To Catalyze the Electrochemical $\mathrm{CO}_{2}$-toMethanol Conversion by Biomimetic $2 \mathrm{e}^{-}+2 \mathrm{H}^{+}$Transferring Molecules. J. Am. Chem. Soc. 2016, 138, 1017-1021.

(15) Portenkirchner, E.; Enengl, C.; Enengl, S.; Hinterberger, G.; Schlager, S.; Apaydin, D.; Neugebauer, H.; Knoer, G.; Sariciftci, N. S. A Comparison of Pyridazine and Pyridine as Electrocatalysts for the Reduction of Carbon Dioxide to Methanol. ChemElectroChem 2014, 1, 1543-1548.

(16) Yuan, J.; Zheng, L.; Hao, C. Role of Pyridine in Photoelectrochemical Reduction of $\mathrm{CO}_{2}$ to Methanol at a CuInS 2 Thin Film Electrode. RSC Adv. 2014, 4, 39435-39438. 
(17) Rybchenko, S. I.; Touhami, D.; Wadhawan, J. D.; Haywood, S. K. Study of Pyridine-Mediated Electrochemical Reduction of $\mathrm{CO}_{2}$ to Methanol at $\mathrm{High}^{\mathrm{CO}} \mathrm{C}_{2}$ Pressure. ChemSusChem 2016, 9, 1660-1669.

(18) Morris, A. J.; McGibbon, R. T.; Bocarsly, A. B. Electrocatalytic Carbon Dioxide Activation: The Rate-Determining Step of Pyridinium-Catalyzed $\mathrm{CO}_{2}$ Reduction. ChemSusChem 2011, 4, 191-196.

(19) Lucio, A. J.; Shaw, S. K. Pyridine and Pyridinium Electrochemistry on Polycrystalline Gold Electrodes and Implications for $\mathrm{CO}_{2}$ Reduction. J. Phys. Chem. C 2015, 119, 12523-12530.

(20) Keith, J. A.; Carter, E. A. Theoretical Insights into Electrochemical $\mathrm{CO}_{2}$ Reduction Mechanisms Catalyzed by Surface-Bound Nitrogen Heterocycles. J. Phys. Chem. Lett. 2013, 4, 4058-4063.

(21) Keith, J. A.; Carter, E. A. Electrochemical Reactivities of Pyridinium in Solution: Consequences for $\mathrm{CO}_{2}$ Reduction Mechanisms. Chem. Sci. 2013, 4, 1490-1496.

(22) Lim, C.-H.; Holder, A. M.; Hynes, J. T.; Musgrave, C. B. Reduction of $\mathrm{CO}_{2}$ to Methanol Catalyzed by a Biomimetic Organo-Hydride Produced from Pyridine. J. Am. Chem. Soc. 2014, 136, 16081-16095.

(23) Marjolin, A.; Keith, J. A. Thermodynamic Descriptors for Molecules That Catalyze Efficient $\mathrm{CO}_{2}$ Electroreductions. ACS Catal. 2015, 5, 1123-1130.

(24) Lessio, M.; Senftle, T. P.; Carter, E. A. Is the Surface Playing a Role during Pyridine-Catalyzed $\mathrm{CO}_{2}$ Reduction on p-GaP Photoelectrodes? ACS Energy Lett. 2016, 1 , 464-468.

(25) Yan, Y.; Zeitler, E. L.; Gu, J.; Hu, Y.; Bocarsly, A. B. Electrochemistry of Aqueous Pyridinium: Exploration of a Key Aspect of Electrocatalytic Reduction of $\mathrm{CO}_{2}$ to Methanol. J. Am. Chem. Soc. 2013, 135, 14020-14023.

(26) Zeitler, E. L.; Ertem, M. Z.; Pander, J. E., III; Yan, Y.; Batista, V. S.; Bocarsly, A. B. Isotopic Probe Illuminates the Role of the Electrode Surface in Proton Coupled Hydride Transfer Electrochemical Reduction of Pyridinium on Pt(111). J. Electrochem. Soc. 2015, 162, H938-H944.

(27) Ertem, M. Z.; Konezny, S. J.; Araujo, C. M.; Batista, V. S. Functional Role of Pyridinium during Aqueous Electrochemical Reduction of $\mathrm{CO}_{2}$ on $\mathrm{Pt}(111)$. J. Phys. Chem. Lett. 2013, 4, 745-748.

(28) Minimal $\mathrm{CH}_{3} \mathrm{CN}$ was required to dissolve $\mathbf{3} / \mathbf{4}$ in water, and so for consistency the same solvent ratio was used all compounds. $\mathrm{LiClO}_{4}$ chosen as the electrolyte due to its ability to dissolve in aqueous/non-aqueous mixtures. 
(29) In our experimental set-up, \% $\mathrm{FE}$ for hydrogen $\left(\mathrm{H}_{2}\right)$ was not determined as $\mathrm{CO}_{2}$ is bubbled through the solution continuously.

(30) Lanning, J. A.; Chambers, J. Q. Voltammetric Study of the Hydrogen Ion/Hydrogen Couple in Acetonitrile/Water Mixtures. Anal. Chem. 1973, 45, 1010-1016.

(31) Lebegue, E.; Agullo, J.; Morin, M.; Bélanger, D. The Role of Surface Hydrogen Atoms in the Electrochem Reduction of Pyridine and $\mathrm{CO}_{2}$ in Aqueous Electrolyte. ChemElectroChem 2014, 1, 1013-1017.

(32) Gennaro, A.; Isse, A. A.; Vianello, E. Solubility and Electrochemical Determination of $\mathrm{CO}_{2}$ in Some Dipolar Aprotic Solvents. J. Electroanal. Chem. Interfac. Electrochem. 1990, 289, 203-215.

(33) Groenenboom, M. C.; Saravanan, K.; Zhu, Y.; Carr, J. M.; Marjolin, A.; Faura, G. G.; Yu, E. C.; Dominey, R. N.; Keith, J. A. Structural and Substituent Group Effects on Multielectron Standard Reduction Potentials of Aromatic N-Heterocycles. J. Phys. Chem. A 2016, 120, 6888-6894.

(34) pKa's in $\mathrm{CH}_{3} \mathrm{CN} / \mathrm{H}_{2} \mathrm{O}$ were experimentally determined. See SI.

(35) Maksić, Z. B.; Barić, D.; Müller, T. Clar's Sextet Rule Is a Consequence of the $\sigma-$ Electron Framework. J. Phys. Chem. A 2006, 110, 10135-10147.

(36) Chen, Q.-A.; Gao, K.; Duan, Y.; Ye, Z.-S.; Shi, L.; Yang, Y.; Zhou, Y.-G. Dihydrophenanthridine: A New and Easily Regenerable NAD(P)H Model for Biomimetic Asymmetric Hydrogenation. J. Am. Chem. Soc. 2012, 134, 2442-2448.

(37) Lu, L.-Q.; Li, Y.; Junge, K.; Beller, M. Iron-Catalyzed Hydrogenation for the In Situ Regeneration of an $\mathrm{NAD}(\mathrm{P}) \mathrm{H}$ Model: Biomimetic Reduction of $\alpha$-Keto-/ $\alpha-$ Iminoesters. Angew. Chem., Int. Ed. 2013, 52, 8382-8386.

(38) Shul, G.; Weissmann, M.; Bélanger, D. Electrochemical Formation of an Ultrathin Electroactive Film from 1,10-Phenanthroline on a Glassy Carbon Electrode in Acidic Electrolyte. Langmuir 2014, 30, 6612-6621.

(39) Shul, G.; Weissmann, M.; Bélanger, D. Electrochemical Characterization of Glassy Carbon Electrode modified with 1,10-Phenanthroline Groups by Two Pathways: Reduction of the Corresponding Diazonium Ions and Reduction of Phenanthroline. Electrochim. Acta 2015, 162, 146-155.

(40) Lessio, M.; Riplinger, C.; Carter, E. A. Stability of Surface Protons in PyridineCatalyzed $\mathrm{CO}_{2}$ Reduction at p-GaP Photoelectrodes. Phys. Chem. Chem. Phys. 2016, 18, 26434-26443. 
(41) Senftle, T. P.; Lessio, M.; Carter, E. A. Interaction of Pyridine and Water with the Reconstructed Surfaces of $\mathrm{GaP}(111)$ and $\mathrm{CdTe}(111)$ Photoelectrodes: Implications for $\mathrm{CO}_{2}$ Reduction. Chem. Mater. 2016, 28, 5799-5810.

(42) Chen, L. D.; Urushihara, M.; Chan, K.; Nørskov, J. K. Electric Field Effects in Electrochemical $\mathrm{CO}_{2}$ Reduction. ACS Catalysis 2016, 6, 7133-7139.

(43) Oxidative cycling was only conducted in survey CV scans, and was not performed prior to bulk electrolysis experiments of the DHP samples.

(44) Peroff, A. G.; Weitz, E.; Van Duyne, R. P. Mechanistic Studies of Pyridinium Electrochemistry: Alternative Chemical Pathways in the Presence of $\mathrm{CO}_{2}$. Phys. Chem. Chem. Phys. 2016, 18, 1578-1586.

(45) Lim, C.-H.; Holder, A. M.; Hynes, J. T.; Musgrave, C. B. Catalytic Reduction of $\mathrm{CO}_{2}$ by Renewable Organohydrides. J. Phys. Chem. Lett. 2015, 6, 5078-5092.

(46) Froehlich, J. D.; Kubiak, C. P. Homogeneous $\mathrm{CO}_{2}$ Reduction by Ni(cyclam) at a Glassy Carbon Electrode. Inorg. Chem. 2012, 51, 3932-3934.

(47) Yang, N.; Waldvogel, S. R.; Jiang, X. Electrochemistry of Carbon Dioxide on Carbon Electrodes. ACS Appl. Mater. Interfaces 2016, 8, 28357-28371.

(48) Chapovetsky, A.; Do, T. H.; Haiges, R.; Takase, M. K.; Marinescu, S. C. ProtonAssisted Reduction of $\mathrm{CO}_{2}$ by Cobalt Aminopyridine Macrocycles. J. Am. Chem. Soc. 2016, 138, 5765-5768.

(49) Maurin, A.; Robert, M. Noncovalent Immobilization of a Molecular Iron-Based Electrocatalyst on Carbon Electrodes for Selective, Efficient $\mathrm{CO}_{2}$-to-CO Conversion in Water. J. Am. Chem. Soc. 2016, 138, 2492-2495.

(50) Murase, M.; Kitahara, G.; Suzuki, T. M.; Ohta, R. Efficient Catalytic Electrode for $\mathrm{CO}_{2}$ Reduction Realized by Physisorbing Ni(cyclam) Molecules with Hydrophobicity Based on Hansen's Theory. ACS Appl. Mater. Interfaces 2016, 8, 24315-24318.

(51) Lau, G. P. S.; Schreier, M.; Vasilyev, D.; Scopelliti, R.; Grätzel, M.; Dyson, P. J. New Insights Into the Role of Imidazolium-Based Promoters for the Electroreduction of $\mathrm{CO}_{2}$ on a Silver Electrode. J. Am. Chem. Soc. 2016, 138, 7820-7823. 